\title{
PROMISING TREND OF IN SITU BREEDING OF ORIENTAL WhITE-RUMPED VULTURE GYPS BENGALENSIS IN RAIGAD DISTRICT, MAHARASHTRA, INDIA: CONSERVATION IMPLICATIONS FOR RE-INTRODUCTION OF EX SITU POPULATIONS
}

\author{
Satish Pande ${ }^{1}$, Premsagar Mestri $^{2}$, Prashant Deshpande ${ }^{3}$, Amol Warange $^{4}$ \& Anil Mahabal ${ }^{5}$ \\ 1,3,5 Ela Foundation, C-9, Bhosale Park, Sahakarnagar-2, Pune, Maharashtra 411009, India \\ 2 'Gulmohor Colony', Near Chavdar Tale, Mahad, Raigad District, Maharashtra 402301, India \\ ${ }^{4}$ Plot No. 50/A. Sahakarvrinda Soc., R.P. Nagar, Kothrud, Pune, Maharashtra 411038, India \\ ${ }^{1}$ pande.satish@gmail.com (corresponding author), ${ }^{2}$ premsagargm@gmail.com, ${ }^{3}$ detaman@gmail.com, ${ }^{5}$ mahabal.anil@gmail.com
}

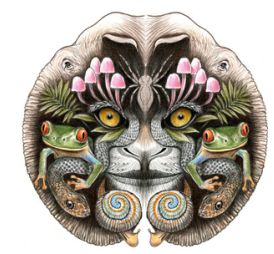

ISSN

Online 0974-7907

Print 0974-7893

OPEN ACCESS
Abstract: The population of Gyps vultures crashed at an alarming rate in India, from $85 \%$ since $1985-86$ to $0 \%$ in 1997-99. There are sporadic records of sightings, wild breeding and captive breeding of Gyps and Neophron Vultures from 2005 to 2010 from various parts of India. We noticed continued, uninterrupted successful nesting of Oriental White-rumped Vultures Gyps bengalensis in their natural habitats in Raigad District, Maharashtra from 2004 to 2011. Their breeding population steadily increased from 10 pairs in 2004-2005 to 22 pairs in 2010-2011 and the nesting success steadily increased from $30 \%$ in 2004-2005 to $70 \%$ in 2010-2011. We feel that the naturally breeding populations are a must for successful re-introduction of the juvenile captive-bred vultures in the wild, and both in situ and ex situ breeding of vultures should be coordinated till the vulture population increases to an acceptable level and stabilizes in the Indian subcontinent. Identification of natural active nest sites is the foremost requirement for safeguarding the breeding of the Oriental White-rumped Vultures in private land by winning peoples' participation.

Keywords: Captive breeding, conservation implications, Gyps bengalensis, in situ breeding, Oriental White-rumped Vulture, reintroduction, wild populations.

Out of the nine species of vultures recorded from India (Ali \& Ripley 1968), the Critically Endangered (BirdLife International 2012) Oriental White-rumped Vulture Gyps bengalensis and the Long-billed Vulture Gyps indicus, have declined by more than $95 \%$ throughout India
(Prakash et al. 2003, 2007; Green et al. 2004; Shultz et al. 2004; Naoroji 2007; Richard et al. 2011). The causes appear to be multi-factorial such as drugs like Diclofenac and Ketoprofen, scarcity of food, habitat loss, pesticide poisoning, and infections (Cunningham et al. 2003; Shultz et al. 2004; Poharkar et al. 2009; Pande et al. 2011). The nesting success of the Oriental White-rumped Vultures dropped from 82\% in 1985-86 to 0\% during 1997-99 in Keoladeo National Park, Bharatpur, Rajasthan (Prakash 1999). Though there are several reports of sightings of Gyps and Neophron vultures from various states in India (Iyer 2005; Pimplapure 2005; Bharos \& Bharos 2010), there are only sporadic records of the successful nesting of Gyps vultures in their natural habitats (Devakar \& Visavadia 2005; Kasambe et al. 2005; Gomathi 2006; Kamble 2011). Breeding of Gyps species in captivity has also been reported recently (Lahkar et al. 2010). While the vulture population crashed at an alarming rate in India, we noticed continued, uninterrupted successful nesting of Oriental White-rumped Vultures in their natural habitats in Raigad District, Maharashtra from 2004 to 2011. The breeding population of the vultures steadily increased from 10 pairs in 2004-2005 to 22 pairs

DOI: http://dx.doi.org/10.11609/JoTT.03330.4106-9 | ZooBank: urn:Isid:zoobank.org:pub:3BCABFEC-FC4B-4135-9C61-28BE67A3DE64

Manuscript details: Ms \# 03330 | Received 10 September 2012 | Final received 17 December 2012 | Finally accepted 29 March 2013

Citation: Pande, S., P. Mestri, P. Deshpande, A. Warange \& A. Mahabal (2013). Promising trend of in situ breeding of Oriental White-rumped Vulture Gyps bengalensis in Raigad District, Maharashtra, India: conservation implications for re-introduction of ex situ populations. Journal of Threatened Taxa 5(7): 4106-4109; http://dx.doi.org/10.11609/JoTT.03330.4106-9

Copyright: (C) Pande et al. 2013. Creative Commons Attribution 3.0 Unported License. JoTT allows unrestricted use of this article in any medium, reproduction and distribution by providing adequate credit to the authors and the source of publication.

Funding: The project was partly funded by Sahyadri Mitra, Mahad and Ela Foundation, Pune.

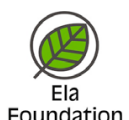

Acknowledgements: We acknowledge the assistance of Forest Department, Thane Division, particularly Mr. Sarfaraj Khan, Up-van Sanrakshak, Roha; Suresh Salunkhe, Range Forest Officer, Mahad; S. Rajwade, Range Forest Officer, Mhasla and B. Gornak, Vanpal, Mhasla. We thank Kumar Pawar and Sanjay Khatavkar for assistance. 
in 2010-2011. Similarly the nesting success steadily increased from 30\% in 2004-2005 to 70\% in 2010-2011. We feel that the naturally breeding populations are a must for successful re-introduction of the juvenile captive-bred vultures in the wild, and both in situ and ex situ breeding of vultures should be coordinated till the vulture population increases to an acceptable level and stabilizes in the Indian subcontinent.

\section{Methods}

All observations of vultures were made during their breeding season (October-April) and later in each of the years from 2004 till 2011. Observations of the Oriental White-rumped Vulture were made at six independent breeding sites, at the foothills of the northern Western Ghats, two each in Mhasala Taluka $\left(18^{\circ} 06^{\prime} \mathrm{N} \& 73^{\circ} 08^{\prime} \mathrm{E}\right)$, Mangao Taluka ( $\left.18^{\circ} 17^{\prime} \mathrm{N} \& 73^{\circ} 17^{\prime} \mathrm{E}\right)$, and from the coastal region in Shriwardhan $\left(18^{\circ} 08^{\prime} \mathrm{N} \& 73^{\circ} 14^{\prime} \mathrm{E}\right)$ Taluka, in Raigad District, Maharashtra. The habitat of the first two sites is semi-evergreen type of forest while the last locality is coconut plantation near human habitation in the coastal region. All the localities were private lands outside protected areas. Weekly visits were made at all the sites and observations were made about the breeding behavior of adults, appearance of chicks in the nest and the feeding of the chicks in the nest and during the branching period by adults. For observing the nesting success we noted the number of young fledged from each nest in the entire study area. We also looked for nest occupation or abandonment. For those nests that were on the trees on the hill slopes, we made observations from a high vantage point with the help of binoculars. For other nests on the coastal region that were on the plains, observations were made by climbing on neighboring trees. All observations were made from a distance of about 25-40 $\mathrm{m}$ from the nest.

\section{Results}

We regularly observed some vultures in the study area from 2004 to 2011. All sites of the Oriental Whiterumped Vulture were about $30-40 \mathrm{~km}$ from each other, encompassing an area of approximately $2025 \mathrm{~km}^{2}$. In the year 2004-2005 six active breeding sites were recorded. Subsequently in 2005-2006 onwards till 2010-2011, only three sites remained active, one in each taluka.

The breeding season commenced in the third week of October; Ali \& Ripley (1968) mention that nesting begins in November. In various sites, all the nests of the Oriental White-rumped Vulture were observed only on trees in the semi-evergreen forest. Only one active nest was seen on each tree. In one case two nests were seen on one tree but only one was active. The vultures used nine trees species for nesting, Mango Mangifera indica, Coconut Cocos nucifera, Arjuna Terminalia cuneata, Behada Terminalia bellirica, Devil Tree Alstonia scholaris, Beach Mahogany Calophyllum inophyllum, False Hemp Tree Tetramelis nudiflora, Indian Tulip Tree Thespesia populnea and Fishtail Palm Caryota urens, most located on private land. The average height of the trees on which the nests were built was $27 m$ ( $n=15$; range $20-43$ $\mathrm{m})$. The average height of the nest from the ground was 21.2m ( $n=15$; range 15-35 m). However, in Anjarale, Murud and Deobag villages in coastal Maharashtra, seven breeding pairs were observed only on Cocos nucifera (Kamble 2011).

The number of nests in our study ranged from 11 in 2004-2005 to 25 in 2010-2011, of which, the total active nests ranged from 10 to 22 (Table 1 ). Further the localitywise nest count during the study period is shown in Table 2. The maximum number of nests in one site, in Mhasla Taluka in 2010-2011 was 16 nests. The species is known to breed in colonies and also scavenges in flocks (Hume \& Oates 1889-1890). During our observations in 20092010, in three nests in Mhasala Taluka, incubation was abandoned and no young fledged and the cause was not

Table 1. The population of Oriental White-rumped Vultures Gyps bengalensis from the year 2004 to 2011 in Raigad District, Maharashtra. It shows breeding adults, non-breeding birds and newly fledged birds, with total numbers of nests and active nests. * Non-breeders include sub-adults and adults.

\begin{tabular}{|l|c|c|c|c|c|c|c|}
\hline & $\mathbf{2 0 0 4 / 5}$ & $\mathbf{2 0 0 5 / 6}$ & $\mathbf{2 0 0 6 / 7}$ & $\mathbf{2 0 0 7 / 8}$ & $\mathbf{2 0 0 8 / 9}$ & $\mathbf{2 0 0 9 / 1 0}$ & $\mathbf{2 0 1 0 / 1 1}$ \\
\hline Total nests & 11 & 14 & 15 & 20 & 23 & 25 & 25 \\
\hline Total active nests & 10 & 12 & 15 & 16 & 19 & 22 & 22 \\
\hline Breeding adults & 20 & 24 & 30 & 32 & 38 & 44 & 44 \\
\hline Non-breeders* & 10 & 11 & 5 & 10 & 11 & 12 & 12 \\
\hline Young fledged & 03 & 03 & 05 & 09 & 13 & 14 & 16 \\
\hline Nesting success & $30 \%$ & $25 \%$ & $33.3 \%$ & $56.3 \%$ & $68.4 \%$ & $63.6 \%$ & $69.5 \%$ \\
\hline
\end{tabular}


Table 2. Locality-wise and year-wise nest count during the study period.

\begin{tabular}{|l|c|c|c|c|c|c|c|}
\hline Locality/Year & $\mathbf{2 0 0 4 / 5}$ & $\mathbf{2 0 0 5 / 6}$ & $\mathbf{2 0 0 6 / 7}$ & $\mathbf{2 0 0 7 / 8}$ & $\mathbf{2 0 0 8 / 9}$ & $\mathbf{2 0 0 9 / 1 0}$ & $\mathbf{2 0 1 0 / 1 1}$ \\
\hline Mangao & 0 & 0 & 2 & 2 & 4 & 6 & 5 \\
\hline Mhasala & 2 & 6 & 6 & 11 & 12 & 15 & 16 \\
\hline Shriwardhan & 9 & 8 & 7 & 7 & 7 & 4 & 4 \\
\hline Total Nests & 11 & 14 & 15 & 20 & 23 & 25 & 25 \\
\hline
\end{tabular}

determined. Similarly, in Mhasala Taluka, the Changeable Hawk-Eagle Spizaetus cirrhatus attacked a nest of the vultures once in each year in February 2010 and 2011, when a chick was present in the nest. This eagle nested about $200 \mathrm{~m}$ from the nest site of the vulture only during these two years. The plundered nest was subsequently abandoned. Ali \& Ripley (1968) documented that this species lays only one egg per clutch (we assumed that only one egg was laid per active nest, because we could not ascertain the contents of the nests placed in trees at considerable heights). Nests were reused and new nests were also built during the study period.

Our observation showed that the eggs were laid between 18 October and the first week of December in each year during the study period. The exact duration of incubation and dates of hatching could not be ascertained. However, our observations reveal that the incubation period is at least 40 days. The chicks were first seen in the various nests between the end of November and the fourth week of January during the study period. The chicks fledged during February and early April. Branching period (when the young perch outside the nest on adjacent branches) was up to 45 days from fledging. This is probably the first record of the nestling and branching periods for this species. Feeding of the young by adults outside the nests, but in the same respective locality, was observed up to two years from the time of fledging. We identified the young based on plumage characteristics. Our observations revealed that nesting success (percent young fledged from active nests) increased from 30\% in 2004-2005 to $69 \%$ in 2008-2009. It declined in 2009-2010 to 64\% for unknown reasons, but again increased to $70 \%$ in 2010 2011 (Table 1). The breeding population of vultures in 2004-2005 was 10 pairs and increased to 22 pairs in 2010-2011. Although some vultures were regularly seen at the site throughout the year, there were some periods when no vulture was seen at the site for up to three days at a stretch.

\section{Conservation Implications}

Identification of natural active nest sites is the foremost requirement for safeguarding the breeding of the Oriental White-rumped Vultures in the future. Protecting such nest sites and conserving the existing nest trees on private lands cannot be effectively achieved without winning peoples', participation. The vulture population throughout India appears to be currently stabilizing with the substitution of toxic Diclofenac with Meloxicam (Richard et al. 2011). At present, successful attempts are also being made to breed the Gyps vultures in captive breeding programs (Lahkar et al. 2010). It is vital to note that naturally breeding populations are a must for successful re-introduction of the captive bred vultures in the wild; thereby, captive bred populations will get an opportunity to mingle with wild populations and learn the essentials of survival from their wild kin. Wild flocks of vultures are necessary to ensure the effective naturalization, long term survival and genetic stability of captive bred populations. Considering the present situation of declining vulture populations in India, both in situ and ex situ breeding of vultures should be coordinated till the vulture population increases to an acceptable level and stabilizes in the Indian subcontinent. The conservation importance of natural populations of various species of raptors is evident by the use of such nests for the successful re-introduction of orphaned or captive bred raptors in the wild in various parts of the world, where such chicks have been successfully fostered in the nests of their wild breeding counterparts (Wiemeyer 1981; Gonzalez et al. 1986; Rymon 1990 \& Pande et al. 2004).

\section{REFERENCES}

Ali, S. \& D.S. Ripley (1968). Handbook of the Birds of India and Pakistan together with those of Bangladesh, Nepal, Bhutan and Sri LankaVol. 1. Oxford University Press, New Delhi, 384pp.

Bharos, A.M.K. \& A. Bharos (2010). Recent sightings of Indian Whitebacked Vultures (Gyps bengalensis). Newsletter for Birdwatchers 50(5): 72.

BirdLife International (2012). Gyps bengalensis. In: IUCN 2012. IUCN Red List of Threatened Species. Version 2012.2. <www.iucnredlist. 
org>. Downloaded on 18 April 2013.

Devakar, R.V. \& M.D. Visavadia (2005). Nesting of Vultures in Girnar Hill, Junagadh (Gujarat). Newsletter for Birdwatchers 45(2): 21-22.

Gomathi, N. (2006). Breeding sites of (Gyps bengalensis) and (Gyps tenuirostris) in Katerniaghat Wildlife Sanctuary, Uttar Pradesh. Newsletter for Birdwatchers 46(1): 14-15.

Gonzalez, J.L., B. Heredia, L.M. González \& N. Alonso (1986). Adoption of a juvenile by breeding Spanish imperial eagles during the postfledging period. Raptor Research 20: 77-78.

Green, R.E., I. Newton, S. Shultz, A.A. Cunningham, M. Gilbert, D.J. Pain \& V. Prakash (2004). Diclofenac poisoning as a cause of vulture population declines across the Indian subcontinent. Journa of Applied Ecology 41: 793-800; http://dx.doi.org/10.1111/j.00218901.2004.00954.x

Hume, A.O. \& E.W. Oates (1889-1890) The Nests and Eggs of Indian Birds - 3 volumes. Second edition. R.H. Porter, London, 397pp.

Iyer, M.K. (2005). Sighting of Gyps (Vultures) and Aquila (Eagles) at Dhabla Pound and Thol Bird Sanctuary. Newsletter for Birdwatchers 45(2): 24-25.

Kamble, A.A. (2011). A study on breeding behaviour of Oriental Whitebacked Vulture (Gyps bengalensis) in Anjarle \& Deobag, Maharashtra. Dissertation submitted to Saurashtra University, Rajkot. In Partia Fulfillment of the Master's Degree In Wildlife Science.

Kasambe, R., A. Pimpalapure, J. Wadatkar \& A. Pillarisett (2005). Vulture notes from Vidarbha including Melghat and Tadoba Andhari Tiger Reserves. Newsletter for Birdwatchers 45(5): 77-78.

Lahkar, D., V. Prakash, H.K. Sahu, S. D. Raut, S. K. Datta \& N. Prakash (2010). Feeding ecology of Gyps species of vultures in captivity. Newsletter for Birdwatchers 50(5): 65-69.

Naoroji, R. (2007). Birds of Prey of the Indian Subcontinent. Om Books International. New Delhi, 692pp.

Pande, S., A. Pawashe, \& B. Pednekar (2004). How long is too long? A case of fostering nestling Bonelli's Eagles Hieragetus fasciatus. Journal of Raptor Research 38: 381-382.

Pande, S., P. Pandit, A. Ponkshe, R. Mone, S. Pawar \& A. Mishra (2011). Behavioural and virological studies on a rescued Orienta White-backed Vulture Gyps bengalensis from western Maharashtra,
India. Journal of Threatened Taxa 3(1): 1490-1492; http://dx.doi. org/10.11609/JoTT.02471.1490-2

Pimplapure, A. (2005). Sighting of Egyptian Vulture (Neophron percnopterus) in a flock. Newsletter for Birdwatchers 45(2): 26.

Poharkar, A., P.A. Reddy, V.A. Gadge, S. Kolte, N. Kurkure, \& S. Shivaji (2009). Is malaria the cause for decline in the wild population of the Indian White-backed Vulture (Gyps bengalensis)? Current Science 96: 553-558.

Prakash, V. (1999). The status of vultures in Keoladeo National Park, Bharatpur, Rajasthan, with special reference to population crash in Gyps species. Journal of the Bombay Natural History Society 96(3): 365-378.

Prakash, V., D.J. Pain, A.A. Cunningham, P.F. Donald, N. Prakash, A. Verma, R. Gargi, S. Sivakumar \& A.R. Rahmani (2003). Catastrophic collapse of Indian White-backed Gyps bengalensis and Long-billed Gyps indicus vulture populations. Biological Conservation 109: 381390; http://dx.doi.org/10.1016/S0006-3207(02)00164-7

Prakash, V., R.E. Green, D.J. Pain, S.P. Ranade, S. Saravanan, N. Prakash, R. Venkitachalam, R. Cuthbert, A.R. Rahmani \& A.A. Cunningham (2007). Recent changes in populations of resident Gyps vultures in India. Journal of the Bombay Natural History Society 104(2): 127-133.

Richard, C.J., V. Prakash, M. Saini, S. Upreti, D. Swarup, A. Das, R.E. Green \& M. Tagart (2011). Are conservation actions reducing the threat to India vulture populations? Current Science 101(11): 14801484.

Rymon, L. (1990). Osprey nestlings fostered by hacked adults two weeks after predation of their young. Journal of Raptor Research 24: 71-72.

Shultz, S., H.S. Baral, S. Charman, A.A. Cunningham, D. Das, G.R. Ghalsasi, M.S. Goudar, R.E. Green, A. Jones, P. Nighot, D.J. Pain \& V. Prakash (2004). Diclofenac poisoning is widespread in declining vulture populations across the Indian subcontinent. Proceedings of the Royal Society B 271: S458-S460; http://dx.doi.org/ 10.1098/ rsbl.2004.0223

Wiemeyer, S.N. (1981). Captive propagation of bald eagles at Patuxent Wildlife Research Center and introductions into the wild. Raptor Research 15: 68-82. 